\title{
Determination of Rennet Clotting Time by Texture Analysis Method
}

\author{
Zerrin Yuksel \\ Department of Food Technology, Bayramiç Vocational Collage, Çanakkale Onsekiz Mart University, Çanakkale, Turkey. \\ Email: zyuksel@comu.edu.tr
}

Received May $21^{\text {st }}, 2013$; revised June $21^{\text {st }}, 2013$; accepted June $28^{\text {th }}, 2013$

Copyright (C) 2013 Zerrin Yuksel. This is an open access article distributed under the Creative Commons Attribution License, which permits unrestricted use, distribution, and reproduction in any medium, provided the original work is properly cited.

\begin{abstract}
In this study, texture analysis method was used for the determination of rennet flocculation time $\left(\mathrm{t}_{\text {floc }}\right)$ and rennet clotting time ( $\left.\mathrm{t}_{\text {clot }}\right)$ of rennet-induced reconstitued milk samples with different $\mathrm{CaCl}_{2}$ concentrations. The rennet flocculation time (RFT) and rennet clotting time (RCT) were also determined by using the Berridge test and sensory evaluation. The hardness value versus renneting time curves derived from texture analysis gave a good modified exponential relationship for each $\mathrm{CaCl}_{2}$ concentration and the curves were used to calculate flocculation time and clotting time parameters. It was found that the parameters $\left(t_{\text {floc }}\right.$ and $\left.t_{\text {clot }}\right)$ appeared strongly correlated with RFT and RCT, respectively. Texture analysis was proved as a suitable method to control the rennet-induced coagulation and determine the rennet clotting time. It was also determined that enrichment of milk with $\mathrm{CaCl}_{2}$ leaded to a decrease in flocculation and clotting times and an increase in rate of clotting and gel hardness.
\end{abstract}

Keywords: Rennet Flocculation Time; Rennet Clotting Time; Texture Analysis; Hardness; Rennet $\mathrm{Gel} ; \mathrm{CaCl}_{2}$

\section{Introduction}

The first stage of cheese manufacture is the conversion of liquid milk to cheese curd. After the addition of chymosin to the milk, there is little apparent reaction for some time and then the milk coagulates rapidly. During this lag phase, the enzyme hydrolyses the $\kappa$-casein which stabilizes the casein micelles. This phenomenon, which is the first step of cheesemaking, results from two stages. The enzymatic proteolysis forms the first or primary phase. In this phase, milk-clotting enzymes spli $\kappa$-casein at the junction between the para- $\kappa$-casein and macropeptide moieties, i.e. in bovine $\kappa$-casein, at the $\mathrm{Phe}_{105}$ Met $_{106}$ bond. When sufficient amount of $\kappa$-casein has been hydrolyzed, the destabilized micelles begin to aggregate and this eventually leads to a three-dimensional cheese curd [1,2]. In casein micelles, proteolysis of a small number of $\kappa$-casein molecules will have much less effect on the aggregation properties, since the micelles contain many hundreds or even thousands of such molecules. The para- $\kappa$-casein produced in the micelles by renneting can only aggregate when the whole micelle is capable of aggregating, and it is this that causes the lag phase before aggregation is observed. Renneted micelles appear to be incapable of aggregating until about $60 \%$ $80 \%$ of their $\kappa$-casein has been destroyed, after which the concentration of micelles capable of aggregating increases rapidly. This behavior can be explained either by the loss of surface charge during renneting or by loss of steric stabilization [1].

The aggregation rate of renneted micelles is unaffected by the concentration of rennet or by the size of the micelles. However, it is very sensitive to the concentration of ionic calcium. It is thought that the ionic calcium does not directly affect the enzymatic phase, although addition of $\mathrm{CaCl}_{2}$ does reduce milk $\mathrm{pH}$, which accelerates the hydrolysis reaction. However, addition of calcium reduces the rennet coagulation time, even at constant milk $\mathrm{pH}$, and flocculation occurs at a lower degree of $\kappa$-casein hydrolysis. Addition of calcium also increases the rate of firming of rennet-induced milk gels and firmness of the gel. This effect of ionic calcium could be explained by the masking of charged groups and the hydrophobicity increase [3].

The most easily detected outcome of chymosin proteolysis and rennet clotting is the visible observation of the presence of flocs in a milk sample in a rotating tube. The time taken for their appearance is defined as the rennet 
coagulation time, and for the cheese producers interested in the activity of an enzyme preparation, this may be the only quantity of interest [1]. Numerous devices have been developed to study and control of phenomena occurred during the rennet-induced coagulation due to the importance of the curd cutting time on the final cheese quality [4]. Various laboratory techniques have also been described for measuring visco-elastic properties of milk gels as a reference for cheese making; the most widely used are Formagraph and low-amplitude dynamic shear measurements [5]. Payne et al. [6] used a diffuse reflectance technique to predict optimal cutting time as measured by Formagraph on composite milks prepared from varying proportions of cream, skim milk and condensed skim milk. They found that the inflection point of the sigmoidal phase of the diffuse reflactance curve was well correlated with the Formagraph measure of the rennet clotting time. It was compared that the performance of a NIR transmission probe with the Formagraph used skimmed and whole milk and it has found that there was a good correlation between the time to inflection point of the transmission signal and the rennet coagulation time by the Formagraph.

Sharma et al. [7] evaluated on-line measurements of coagulation time and coagulation firmness of renneted milk using a torsional vibration technique, namely a Nametre viscometer. It was defined as the point where complex viscosity became higher than the initial value at rennet addition using a coagulation time parameter.

Turbidity or light scattering methods were used for following early aggregation phase while the gel formation and development are most monitored by rheometer. Each technique suffers from limitations. Light scattering requires a dilute dispersion of particles so that only singly scaretted photons are collected at the detector. Studies using light scattering are thus limited to initial stage of aggregation, where growth of molecular weight or degree of polimerization is obtained as function of reaction time. Rheological measurements suffer from the opposite failing. There, the limitation is instrument-sensitivity and a detectable signal is realized only after the reaction has progressed to a significant extent [1].

Some of the techniques mentioned above have also been used to determine the influence of various factors such as temperature, $\mathrm{pH}$, milk composition and $\mathrm{CaCl}_{2}$ concentration on the rennet coagulation process.

In most cases, studies were carried out with using techniques mentioned above. There is no research on determination of both of the rennet flocculation and clotting times with using the texture analysis. The objective of this study is to predict both of the flocculation and clotting times with using results of hardness measurements at different $\mathrm{CaCl}_{2}$ concentrations during the ren- netting.

\section{Materials and Methods}

\subsection{Reconstitued Milk Sample}

Reconstitued milk sample was prepared by reconstituting low-heat skimmed milk powder (purchased from ENKA Dairy Co., Konya, Turkey) at ratio of $12 \mathrm{~g} / 100 \mathrm{ml}$ deionized [8]. $\mathrm{CaCl}_{2}$ (Merck, Germany) was added to obtained concentrations of $0.02 \%$ (Sample A), $0.04 \%$ (Sample B), $0.06 \%$ (Sample C), 0.08\% (Sample D), 0.10\% (Sample E), $0.12 \%(w / v)$ (Sample F). Total protein content of the reconstitued milk was $3.2 \%$, w/w.

\subsection{Rennet Coagulation Experiment}

Maxiren $600^{\circledR}$ (DSM Foods, Delft, The Netherlands) with a declared activity of $160 \mathrm{IMCUmL}^{-1}$ was used for renneting of the reconstitued milk. A solution of rennet was prepared daily by diluting $1 \mathrm{~mL}$ of Maxiren $600^{\circledR}$ in $100 \mathrm{~mL}$ of deionized water. Rennet solution was added to the reconstitued milk at $32^{\circ} \mathrm{C}$ to a final concentration of $0.01 \%(\mathrm{v} / \mathrm{v})$. Samples were divided into several assays $(200 \mathrm{ml}$ each) for preparing renneting time-series $(0-70$ $\min )$.

\subsection{Measurement of Gel Hardness}

The hardness $(\mathrm{N})$ of viscoelastic rennet gels was determined by means of texture analysis. A texturometer model TA-PLUS (Lloyd Instruments, Fareham, UK) with a $10 \mathrm{~N}$ cross-head was used to measure the hardness of rennet gels. The measuring probe consisted of an acrylic cone (diameter $4 \mathrm{~cm}$ and $60^{\circ}$ angle) was thrust into gels in cylindrical containers (200 $\mathrm{ml}$ in volume) by the $80 \%$ compression depth from surface. A single compression method (one cycle) was applied at a constant crosshead velocity of $2 \mathrm{~mm} \cdot \mathrm{s}^{-1}$. The hardness value of the gels was calculated on line by using the software, Nexygen $^{\circledR} 2.0$ software (Lloyd Instruments, Fareham, UK). Exponential relationships between rennetting time $(\mathrm{t}, \mathrm{min})$ and hardness value $(H, \mathrm{~N})$ have been determined in the rennet gels at different $\mathrm{CaCl}_{2}$ concentrations. It was found that the curves fitted "modified exponential model" (correlation coefficient, $r \geq 0.98$; standard error, $\mathrm{SE}<0.006$ were found). According to this model, equation derived from the curves was given as such;

$$
H=H_{o} \cdot \exp (a / \mathrm{t})
$$

where $H$ is hardness value $(\mathrm{N}), \mathrm{t}$ is the time after the addition of rennet (min), $H_{o}$ is the initial hardness value $(\mathrm{N})$, $a$ is the regression coefficient.

Four different parameters were extracted from the hardness changes according to renneting time; rennet clotting time $\left(\mathrm{t}_{\text {clot }}\right)$ corresponding to the time when the 
hardness value was $0.12 \mathrm{~N}$ (maximum hardness value for Sample A), flocculation time $\left(\mathrm{t}_{\mathrm{floc}}\right)$ corresponding to the time when the hardness value became greater than the initial value, rate of clotting $\left(\mathrm{r}_{\text {clot }}\right)$ corresponding to the rate of hardness increase, and final hardness $\left(\mathrm{H}_{70}\right)$ corresponding to the hardness value at $70 \mathrm{~min}$ after the addition of rennet. Curve Expert 1.3 (a comprehensive curve fitting system for Windows) was used to evaluate Hardness-renneting time curves.

\subsection{Determination of Rennet Flocculation and Clotting Times}

The rennet floculation time (RFT), the time from addition of the rennet to the first formation of visible floccules, was determined according to the method by Berridge [8]. The rennet clotting time (RCT) was determined with sensory evaluation by using a spatula by means of traditionally detection of curd-cutting time.

\subsection{Total Protein Content}

The total protein content of reconstituted milk was determined by Bradford method [9].

\subsection{Calcium Ion Activity}

Calcium ion activity of the reconstitued milk samples was determined with an Ion Analyzer (Orion, Model 407 A, USA) and an ion selective electrode (Sartek, UK).

\section{7. pH Measurements}

$\mathrm{pH}$ values of the reconstitued milk samples were determined with using a $\mathrm{pH}$ meter (Sartorius PB-20, Germany).

\subsection{Statistical Analysis}

Each experiment was carried out in triplicate. The data were analyzed statistically by using SPSS for Windows ${ }^{\circledR}$ software (SPSS Inc., Chicago, IL, USA).

\section{Results}

The hardness values of the samples measured during 70 min after the addition of rennet were shown from Figure 1. It was observed that the hardness was increased to a maximum and it was then kept almost constant for all $\mathrm{CaCl}_{2}$ concentration during the renneting. There was also a lag phase observed at the samples added $\mathrm{CaCl}_{2}$ at below of $0.10 \%$. The differences between slopes of the curves and length of the lag phase obtained by different $\mathrm{CaCl}_{2}$ concentrations, allowed to the determination of the rennet flocculation and clotting times and the explanation of the effect of $\mathrm{CaCl}_{2}$ on the renneting with using texture analysis method.

Plotting the hardness value as a function of the renneting time gave a good modified exponential relationship (correlation coefficient $\geq 0.98$; standard error $<$ 0.006) for each $\mathrm{CaCl}_{2}$ concentrations. Rennet clotting

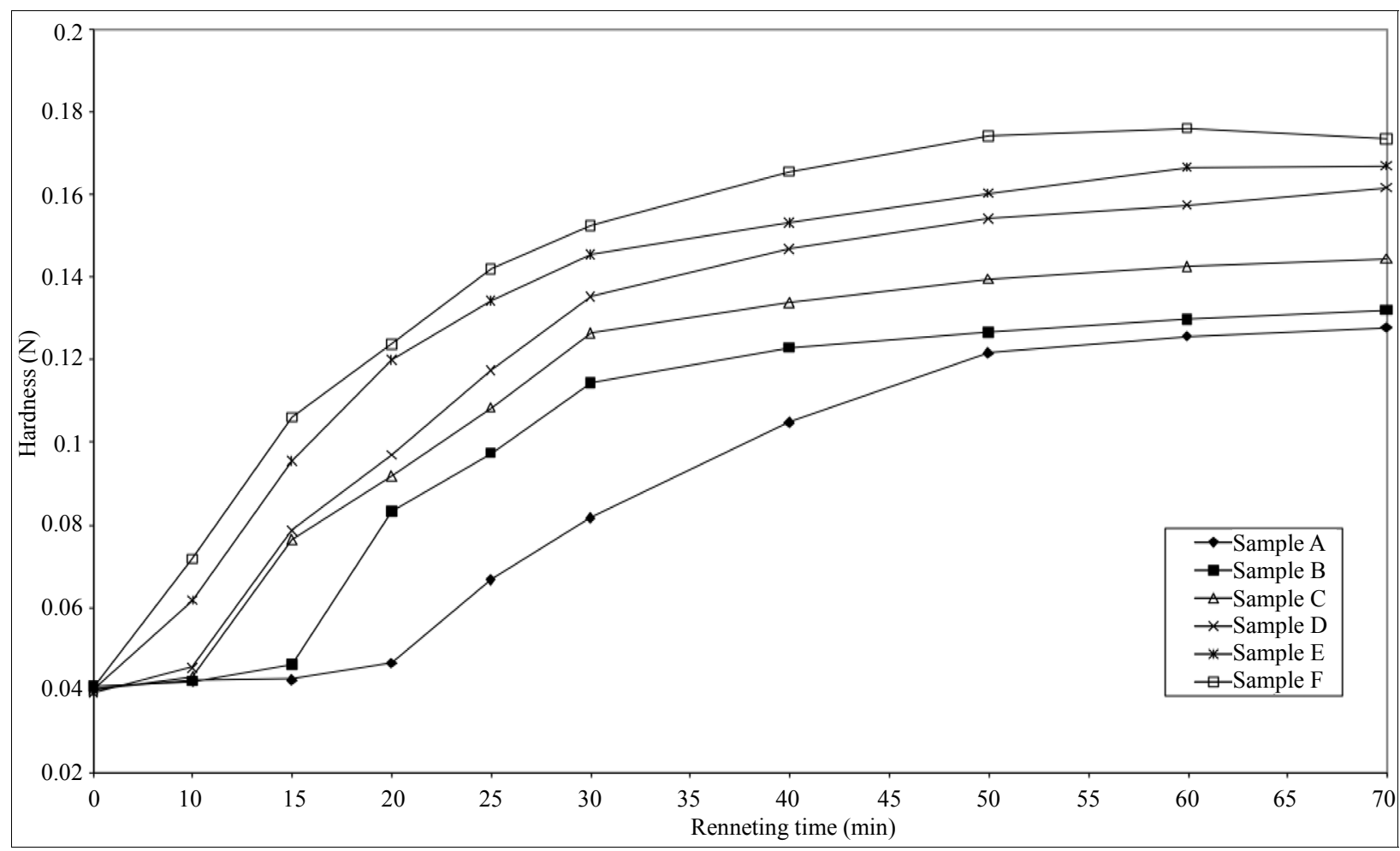

Figure 1. Hardness values of the samples during the renneting. 
time $\left(\mathrm{t}_{\text {clot }}\right)$, flocculation time $\left(\mathrm{t}_{\text {floc }}\right)$ and Hardness value at 70 min after the addition of rennet $\left(\mathrm{H}_{70}\right)$ were determined by using the equation $H=H_{o} \cdot \exp (a / \mathrm{t})$ derived from the curves, where $H$ was hardness value $(\mathrm{N})$, $\mathrm{t}$ was the time after the addition of rennet (min) (Table 1). For all $\mathrm{CaCl}_{2}$ concentrations, $t_{\text {floc }}$ values were calculated for the hardness value $(0.05 \mathrm{~N})$ that was greater than the initial value as an observed lag phase on the diagrams. And $t_{c l o t}$ values of the all samples were calculated for $0.12 \mathrm{~N}$, which was the maximum hardness value of the lowest, $\mathrm{CaCl}_{2}$ induced sample A. The renneting time for hardness value of $0.12 \mathrm{~N}$ was assumed as curd-clotting time of sample A. On the other hand, the sample A showed the longest rennet clotting time. Because the sample A reached to the curd-clotting maturity at this hardness, the time needed for to reach to this hardness value $(0.12 \mathrm{~N})$ of the other samples were used for calculation and comparation of rennet flocculation and clotting times of the samples. According to these assumptions, it was used the follow- ing equations;

$$
\begin{aligned}
& \mathrm{t}_{\text {floc }}=-a /\left(2.99+\ln H_{o}\right) \\
& \mathrm{t}_{\text {clot }}=-a /\left(2.12+\ln H_{o}\right)
\end{aligned}
$$

Rate of clotting values $\left(\mathrm{r}_{\text {clot }}, \mathrm{N} / \mathrm{min}\right.$ ) were calculated from the slope of the plot of hardness versus renneting time. $r_{\text {clot }}$ values corresponding to the rate of hardness increase as a function of renneting time were presented in Table 1.

It was also shown from Table 2 the rennet flocculation time (RFT) and rennet clotting time (RCT) determined by Berridge method and sensory evaluation, respectively. It was found that the time parameters $\left(\mathrm{t}_{\text {floc }}\right.$ and $\left.\mathrm{t}_{\text {clot }}\right)$ derived from the hardness changes according to the renneting time which were in correlation with the RFT and RCT (determination coefficients, $\mathrm{R}^{2}=0.993$ for $\mathrm{t}_{\text {floc }}-\mathrm{RFT}$ line and $\mathrm{R}^{2}=0.999$ for $\mathrm{t}_{\text {clot }}-\mathrm{RCT}$ line). The relationship was validated on the samples at different $\mathrm{CaCl}_{2}$ concentrations $(0.02 \%-0.12 \%)$ (Figure 2$)$.

Table 1. Rennet coagulation parameters derived from hardness-renneting time curves ( $t_{\text {floc }}$, flocculation time; $t_{\text {clot }}$ clotting time; $\mathrm{H}_{70}$, hardness value at $\mathbf{7 0} \mathrm{min}$ after the addition of rennet; $\mathbf{r}_{\text {clot }}$, rate of clotting).

\begin{tabular}{ccccccc}
\hline & Sample A & Sample B & Sample C & Sample D & Sample E & Sample F \\
\hline $\mathbf{t}_{\text {floc }}(\mathbf{m i n})$ & $18.80 \pm 1.0$ & $12.23 \pm 0.7$ & $10.19 \pm 1.2$ & $9.34 \pm 0.6$ & $7.30 \pm 0.8$ & $6.75 \pm 0.5$ \\
$\mathbf{t}_{\text {clot }}(\mathbf{m i n})$ & $54.21 \pm 1.5$ & $42.31 \pm 1.6$ & $31.88 \pm 2.2$ & $26.00 \pm 1.8$ & $20.46 \pm 2.0$ & $17.80 \pm 1.5$ \\
$\mathbf{H}_{\mathbf{7 0}}(\mathbf{N})$ & $0.133 \pm 0.015$ & $0.138 \pm 0.02$ & $0.150 \pm 0.01$ & $0.163 \pm 0.01$ & $0.169 \pm 0.012$ & $0.179 \pm 0.019$ \\
$\mathbf{r}_{\text {clot }}(\mathbf{N} / \mathbf{m i n})$ & $2.44 \times 10^{-3}$ & $2.91 \times 10^{-3}$ & $3.96 \times 10^{-3}$ & $4.37 \times 10^{-3}$ & $4.92 \times 10^{-3}$ & $5.08 \times 10^{-3}$ \\
\hline
\end{tabular}

\begin{tabular}{|c|c|c|c|c|c|c|}
\hline & Sample A & Sample B & Sample C & Sample D & Sample E & Sample F \\
\hline $\mathbf{p H}$ & $6.76 \pm 0.05$ & $6.68 \pm 0.05$ & $6.62 \pm 0.05$ & $6.58 \pm 0.05$ & $6.52 \pm 0.05$ & $6.47 \pm 0.05$ \\
\hline$\left[\mathrm{Ca}^{2+}\right](\mathbf{p p m})$ & $61 \pm 1.2$ & $72 \pm 1.0$ & $90 \pm 1.5$ & $110 \pm 1.5$ & $135 \pm 2.0$ & $162 \pm 2.2$ \\
\hline RFT (min) & $19.17 \pm 1.2$ & $13.30 \pm 1.0$ & $11.10 \pm 0.8$ & $9.20 \pm 0.5$ & $7.75 \pm 0.5$ & $6.50 \pm 0.7$ \\
\hline RCT (min) & $55.50 \pm 1.8$ & $42.75 \pm 2.0$ & $33.75 \pm 2.4$ & $27.17 \pm 1.5$ & $21.92 \pm 1.8$ & $18.60 \pm 2.0$ \\
\hline
\end{tabular}

Table 2. Rennet flocculation and clotting times (RFT and RCT) of the samples determined by the Berridge method at $32^{\circ} \mathrm{C}$.
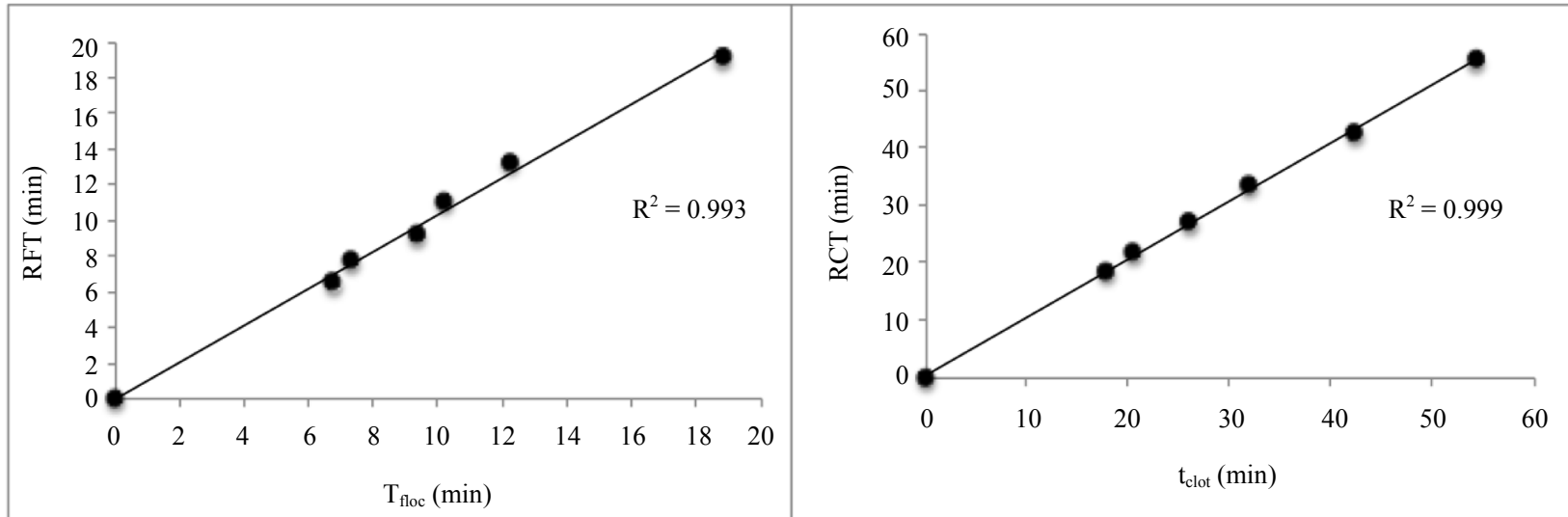

Figure 2. Rennet flocculation time (RFT) determined by Berridge method versus rennet flocculation time ( $t_{\text {floc }}$ ) derived from texture analysis; rennet clotting time (RCT) determined with sensory evaluation versus rennet clotting time ( $\left.t_{\text {clot }}\right)$ derived from texture analysis at different $\mathrm{CaCl}_{2}$ concentrations. $\mathrm{R}^{2}$, determination coefficient. 
Calcium ion activity and $\mathrm{pH}$ values of the samples at different $\mathrm{CaCl}_{2}$ concentrations are presented in Table 2 . $\mathrm{pH}$ of the samples decreased with increasing $\mathrm{CaCl}_{2}$ concentration of the samples because of the "Lewis acid role of the calcium". The addition of $\mathrm{CaCl}_{2}$ not only increased the calcium concentration but also reduced the $\mathrm{pH}$ of milk, resulting in an increased aggregation rate [10]. It was also reported that the percentage of $\kappa$-casein proteolyzed was dependent on milk $\mathrm{pH}$ and ionic calcium content [1].

As it is shown from in Figure 1, decreasing of $\mathrm{CaCl}_{2}$ concentration leads to prolongation of the lag phase of the renneting that represents the preliminary of flocculation stage of para- $\kappa$-casein micelles. Both of $t_{\text {floc }}-t_{\text {clot }}$ and RFT-RCT decreased with increasing $\mathrm{CaCl}_{2}$ concentration (Table 1 and 2). $\mathrm{CaCl}_{2}$ has also leaded to an increase in the gel hardness during the coagulation process. The hardness value at $70 \mathrm{~min}$ after the addition of rennet $\left(\mathrm{H}_{70}\right)$ increased with increasing $\mathrm{CaCl}_{2}$ concentration. Rate of clotting $\left(r_{\text {clot }}\right)$ also increased with increasing $\mathrm{CaCl}_{2}$ concentration (Table 1).

\section{Discussion}

In this study, the milk samples were characterized by different rennet coagulation properties due to $\mathrm{CaCl}_{2}$ added at different concentration to the reconstituted milk. Different $\mathrm{CaCl}_{2}$ concentration of rennet gels allowed evaluation of the method on the samples characterized by different rennet flocculation and clotting times. Two different methods were used and compared to determine rennet flocculation and clotting times of the rennet gels. It was showed that the textural analysis allowed determining both of the rennet flocculation and clotting times. There are many techniques in the literature provided to determine or predict individually early aggregation phase and gel formation-development. Initial aggregation phase of rennetting was generally followed by some methods such as using turbidity or light scaretting whereas the gel formation and development was monitored by another method such as rheometer[1]. However, in this study it was found that the hardness measurement (texture analysis) allowed monitoring the both of early phase and curding cutting step during the rennetting via evaluation of the time parameters $\left(\mathrm{t}_{\text {floc }}\right.$ and $\left.\mathrm{t}_{\mathrm{clot}}\right)$.

Castillo et al. [11] studied on prediction of both gelation time and cutting time in Cottage cheese-type gels and monitored the coagulation process simultaneously using a light backscatter sensor, a rheometer and a $\mathrm{pH}-$ meter. It was developed the models for the prediction of the rheologically defined gelation time using light backscatter and for the prediction of cutting time using light backscatter. It was determined gelation time by using an equation and cutting time by using another equation.
However, in this study one method based on texture analysis during the renneting was provided determination of rennet flocculation and clotting times as a function of hardness. This is confirmed that the texture analysis method was sensitive to all stages of renneting. It was showed that determination of rennet flocculation and clotting times with this method is possible for all given $\mathrm{CaCl}_{2}$ concentrations. It was exposed that flocculation and clotting times can be determined by using the same equation $H=H_{o} \cdot \exp (a / \mathrm{t})$, where $H$ have taken values of 0.05 and $0.12 \mathrm{~N}$ for calculation of $\mathrm{t}_{\text {floc }}$ and $\mathrm{t}_{\text {clot }}$, respectively while constants of $H_{o}$ and $a$ have taken different values for different $\mathrm{CaCl}_{2}$ concentrations.

Besides the determination of the time parameters, this method contributed to the observation of the hardness changes during the renneting and evaluation of influence of $\mathrm{CaCl}_{2}$ on rennet flocculation and coagulation phases. $\kappa$-casein molecules hydrolyse to para- $\kappa$-casein and macropeptide during the lag phase of renneting and aggregation phase starts after the sufficient amount of $\kappa$-casein hydrolyses [1]. The length of lag phase decreases with increasing calcium ion activity. Above of the $0.08 \%$ addition of $\mathrm{CaCl}_{2}$, there was no lag phase observed. This result indicates that the $\mathrm{CaCl}_{2}$ concentration affects the primary phase of renneting. It possibly means that flocculation may occur at a lower degree of $\kappa$-casein hydrolysis at higher ionic calcium concentrations.

It is known that the rate of formation and final strength of rennet gels are influenced greatly by calcium [12]. While not completely understood, it has been shown that ionic calcium influence coagulation and gel formation $[13,14]$. In this study, it was observed that the maximum hardness value of the gels increased and the time needed to reach to the maximum hardness decreased with increasing $\mathrm{CaCl}_{2}$ concentration (Figure 1 and Table 2). Furthermore, an increase of rate of clotting with increasing $\mathrm{CaCl}_{2}$ concentration could be explained mainly by charge neutralization of the negatively charged groups on the micelle surface and possibly by the formation of calcium bridges (Table 1). It is reported that enrichment of milk with calcium leads to an increase in casein aggregation rate during the coagulation process, consequently decreased the flocculation time, and an increase in firmness of rennet gel [4]. It was shown from Table $\mathbf{1}$ and Table 2, rennet flocculation and clotting times decreased with increasing $\mathrm{CaCl}_{2}$ concentration. Sample F $(0.12 \%$ $\mathrm{CaCl}_{2}$ ) has reached maximum $\mathrm{H}_{70}$ values while sample $\mathrm{A}$ $\left(0.02 \% \mathrm{CaCl}_{2}\right)$ has minimum $\mathrm{H}_{70}$ value during the renneting (Table 1). In this study, it was shown that the $\mathrm{CaCl}_{2}$ affects on the both of the primary and secondary phases of renneting with using the texture analysis method.

\section{Conclusion}

In this study, it was indicated that the texture analysis 
could be used accurately for determination of rennet clotting time during the renneting of milk. The obtained hardness values were plotted against the renneting time and evaluated for calculation of rennet flocculation and clotting times. It was found to be important of texture analysis method (hardness measurement) at the rennet-induced samples with different $\mathrm{CaCl}_{2}$ concentrations in terms of prediction both of the flocculation time and clotting time. Furthermore, it was shown that $\mathrm{CaCl}_{2}$ concentration which is the one of the main parameters in the renneting process was affected on the primary and secondary phases of renneting with using the texture analysis method.

\section{Acknowledgements}

The author expresses her gratitude to Prof. Dr. Yaşar Kemal Erdem for his permition for using the texturometer and to Miss Elif Avc1 for her helpings.

\section{REFERENCES}

[1] F. Fox, P. L. H. McSweeney, T. M. Cohan and T. P. Guinee, "Cheese Chemistry, Physics and Microbiology," Vol. 1, Elsevier Ltd., Oxford, 2004.

[2] P. Walstra, J. T. M. Wouters and T. J. Geurts, "Dairy Science and Technology," CRC Press, Taylor and Francis Group, LLC, 2006.

[3] A. Eck and J. C. Gillis, "Cheesemaking_From Science to Quality Assurance," Intercept Ltd., Andover, Hampshire, 2000.

[4] A. H. Klandar, A. Lagaude and D. Chevalier-Lucia, "Assessment of the Rennet Coagulation of Skim Milk: A Comparison Methods," International Dairy Journal, Vol. 17, No. 10, 2007, pp. 1151-1160. http://dx.doi.org/10.1016/j.idairyj.2007.03.005

[5] D. J. O'Callaghan, C. P. O’Donnell and F. A. Payne, “A Comparison of On-Line Techniques for Determination of Curd Setting Time Using Cheesemilk under Different Rates of Coagulation," Journal of Food Engineering, Vol. 41, No. 1, 1999, pp. 43-54.
http://dx.doi.org/10.1016/S0260-8774(99)00072-2

[6] F. A. Payne, C. L. Hicks and P. S. Shen, "Predicting Optimal Cutting Time of Coagulating Milk Using Diffuse Reflectance," Journal of Dairy Science, Vol. 76, No. 1, 1993, pp. 48-61. http://dx.doi.org/10.3168/jds.S0022-0302(93)77322-1

[7] S. K. Sharma, A. R. Hill and G. S. Mittal, "Evaluation of Methods to Measure Coagulation Time of Ultrafiltered Milk," Milchwissenschaft, Vol. 47, No. 11, 1992, pp. 701-704.

[8] N. J. Berridge, "Some Observation on the Determination of the Activity of Rennet," The Analyst, Vol. 77, No. 911, 1952, pp. 57-62. http://dx.doi.org/10.1039/an952770057b

[9] M. M. Bradford, "A Rapid and Sensitive Method for Quantitation of Microgram Quantities of Protein Utilizing the Principle of Protein-Dye Binding," Analytical Biochemistry, Vol. 72, No. 1-2, 1976, pp. 248-254. http://dx.doi.org/10.1016/0003-2697(76)90527-3

[10] A. F. Wolfschoon-Pompo, "Influence of Calcium Chloride Addition to Milk on the Cheese Yield," International Dairy Journal, Vol. 7, No. 4, 1997, pp. 249-254. http://dx.doi.org/10.1016/S0958-6946(97)00005-8

[11] M. Castillo, F. A. Payne, T. Wang and J. A. Lucey, "Effect of Temperature and Inoclulum Concentration on Predicition of Both Gelation Time and Cutting Time. Cottage Cheese-Type Gels," International Dairy Journal, Vol. 16, No. 2, 2006, pp. 147-152. http://dx.doi.org/10.1016/j.idairyj.2005.02.006

[12] J. A. Lucey and P. F. Fox, "Importance of Calcium and Phosphate in Cheese Manufacture," Journal of Dairy Science, Vol. 76, No. 6, 1993, pp. 1714-1724. http://dx.doi.org/10.3168/jds.S0022-0302(93)77504-9

[13] S. I. Shalabi and P. F. Fox, "Influence of pH on the Rennet Coagulation of Milk," Journal of Dairy Research, Vol. 49, No. 1, 1982, pp. 153-157. http://dx.doi.org/10.1017/S0022029900022238

[14] G. J. O. Martin, R. P. W. Williams, C. Choong, B. Lee and D. E. Dunstan, "Comparison of Rennet Gelation Using Raw and Reconstituted Skim Milk," International Dairy Journal, Vol. 18, No. 10-11, 2008, pp. 1077-1080. http://dx.doi.org/10.1016/j.idairyj.2008.05.009 